Gut, 1976, 17, 763-769

\title{
Blood pH: a test for assessment of severity in proctocolitis
}

\author{
R. CAPRILli, P. VERNiA, O. COLANERI, AND A. TORSOLI \\ From the Gastroenterology Unit, 2nd Medical Clinic, University of Rome, Policlinico Umberto I, Rome, \\ Italy
}

SUMMARY Acid base balance was studied in 58 patients with active idiopathic proctocolitis; the condition of 10 of them was complicated by toxic megacolon. Arterial blood $\mathrm{pH}$ increased progressively with increased severity of the colitis and as the lesions became more widespread. Statistically significant differences were observed in $\mathrm{pH}$ values between the mild/moderate and severe forms and between the severe and complicated forms ('toxic megacolon'). A linear correlation was found between $\mathrm{pH}$ and the amount of intestinal gas, pulse rate, and plasma albumin.

In determining prognosis and choice of treatment in proctocolitis a correct evaluation of the severity of the disease is of prime importance. There is no one single parameter on which to base this estimation. Various clinical and haematochemical features are usually taken into consideration, although in a recent statistical analysis only high temperature, tachycardia, bowel actions, and plasma albumin appeared to be of real value in predicting the outcome of the disease (Lennard-Jones et al., 1975).

Current classifications of colitis into mild, moderate, and severe (Caprilli et al., 1975a; Truelove and Witts, 1955) do not indicate that, of the severe forms, some are more severe than others and, when untreated, are almost invariably fatal within a few days. These forms are better known as 'fulminating colitis' and indicate complications such as 'toxic megacolon', perforation of the bowel, and massive haemorrhage (Zer et al., 1972). 'Toxic megacolon', however, is not a sudden event but a situation which gradually develops over a few days or even weeks. Its early signs may be recognized before gross dilatation of the bowel occurs (Caprilli et al., 1975b; Torsoli, 1975).

Previous investigations revealed the presence of metabolic or mixed alkalosis, hypochloraemia, and hypocalcaemia both in the severe form of colitis and in 'toxic megacolon' (Caprilli et al., 1974; Caprilli et

Received for publication 8 June 1976 al., 1975b). The present study was therefore carried out to analyse the relationship between blood pH and the severity of the colitis, the extent of the lesions, and the distribution of gas in the intestine.

\section{Methods}

Studies were carried out in 58 patients with active idiopathic proctocolitis, admitted to the GI Unit of the University of Rome during the period 1973-75. Diagnosis was based on clinical, endoscopic, radiological, and histological findings. Colitis was classified as mild, moderate, or severe according to semiquantitative criteria previously described (Caprilli et al., 1975a). Diagnosis of 'toxic megacolon' was applied to cases presenting distension of the colon of more than $6 \mathrm{~cm}$ (plain abdominal radiography). The extent of the lesions was established from radiological (double contrast enema), colonoscopic, and histological findings. In the patients with 'toxic megacolon' the extent of the lesions was established from the surgical specimen removed. Classification of patients according to the clinical severity of the disease and the extent of the lesions is shown in Table 1.

Arterial blood $\mathrm{pH}, \mathrm{pO}_{2}$, and $\mathrm{pCO}_{2}$ were determined directly on admission using $\mathrm{pH} /$ blood gas analyser 313 (Instrument Laboratory, Italy). Tests were repeated every day in patients with severe colitis and 'toxic megacolon'. Of the various data on acid- 
Table 1 Classification of patients

\begin{tabular}{ll}
\hline Active idiopathic proctocolitis & (58 patients) \\
\hline Severity & 14 \\
Mild & 13 \\
Moderate & 21 \\
Severe & 10 \\
Toxic megacolon & 12 \\
Extent & 19 \\
Rectosigmoid & 27 \\
Left colon & 27 \\
Total colon & \\
\hline
\end{tabular}

base balance, only blood $\mathrm{pH}$ was taken into consideration in this study. $\mathrm{pCO}_{2}$ values were used only to define the metabolic alteration.

Blood pH was compared with the following factors: number of stool evacuations, body temperature, pulse rate, haemoglobin, WBC, ESR, and blood albumin. Intestinal gaseous distension was also planimetrically measured on plain abdominal films. Analysis of variance, Duncan's test, and correlation analysis were used for the statistical evaluation of data.

Results

ACID-BASE ANALYSIS

Acid-base data are reported in Fig. 1. In most patients values were within the range corresponding to metabolic and mixed alkalosis and only a small percentage were within the respiratory alkalosis and normal range. Patients with 'toxic megacolon' tended to fall within the mixed alkalosis range.
PH AND SEVERITY OF COLITIS

$\mathrm{pH}$ values recorded in various degrees of severity of colitis are shown in Fig. 2. No significant difference was found between mild and moderate forms. As the severity of the disease increased, $\mathrm{pH}$ appeared to become progressively higher, the highest values being observed in 'toxic megacolon'. Figure 3 shows thet normal $\mathrm{pH}$ was present only in the mild and moderate forms. A pH over 7.50 invariably indicated severe colitis or 'toxic megacolon'. 'Toxic megacolon' was occasionally found in patients with slight alkalosis, but $50 \%$ of patients were affected in cases of severe alkalosis.

\section{pH AND EXTENT OF COLITIS}

$\mathrm{pH}$ values were seen to increase significantly with the increase in the extent of colonic lesions (Fig. 4). pH values over 7.50 usually corresponded with total colitis.

\section{pH AND CLINICAL FINDINGS}

Blood $\mathrm{pH}$ and other clinical features selected for assessment of the severity of colitis are reported in Table 2. A significant difference in $\mathrm{pH}$ values can be noted between both moderate and severe forms and between severe forms and 'toxic megacolon'.

Figures 5, 6, 7, and 8 show the various degrees of correlation between $\mathrm{pH}$ and pulse rate $(r=0.6036)$, body temperature $(r=0.4806)$. ESR $(r=0.4826)$, and plasma albumin $(r=0.5778)$. No correlation was found between $\mathrm{pH}$ and bowel frequency, haemoglobin, and WBC.

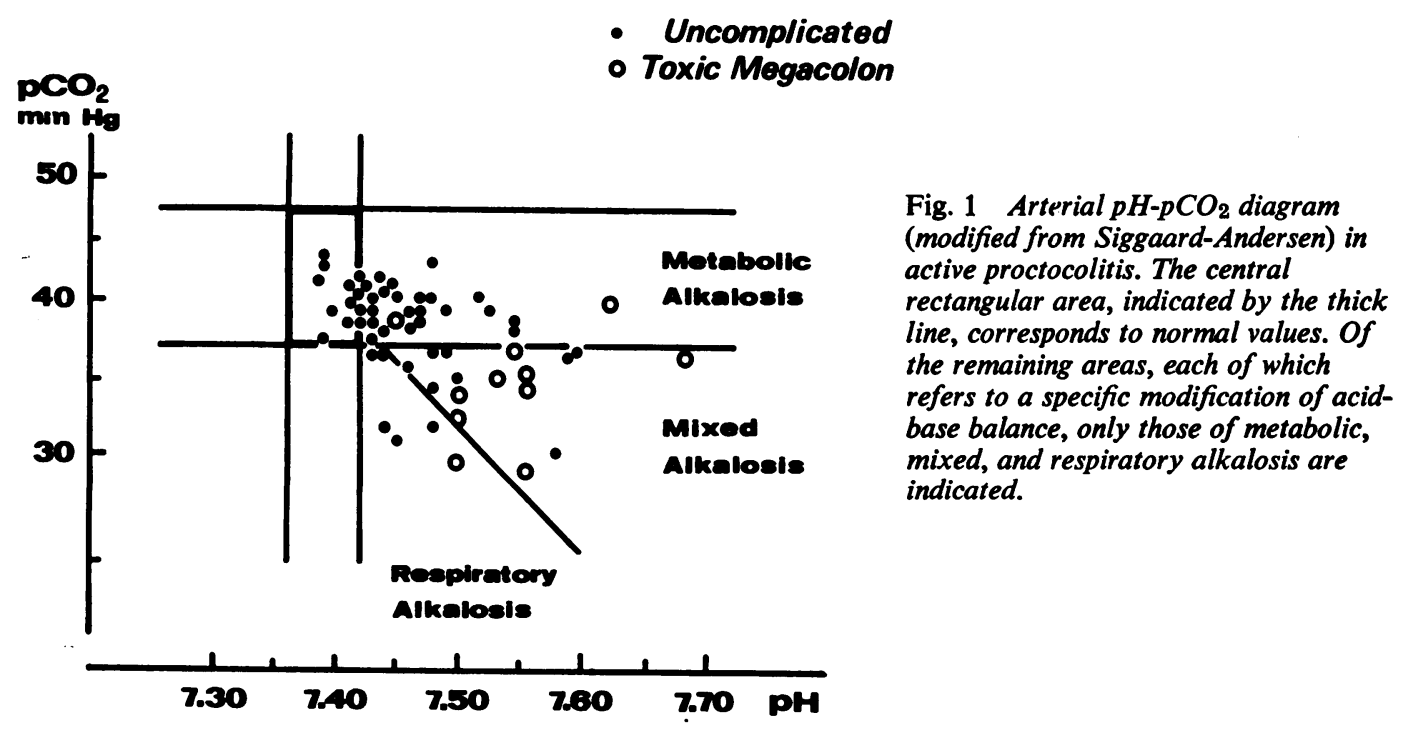

- Uncomplicated

Fig. 1 Arterial $\mathrm{pH}-\mathrm{pCO} \mathrm{CO}_{2}$ diagram (modified from Siggaard-Andersen) in active proctocolitis. The central line, corresponds to normal values. of the remaining areas, each of which refers to a specific modification of acidmixed, and respiratory alkalosis are indicated. 

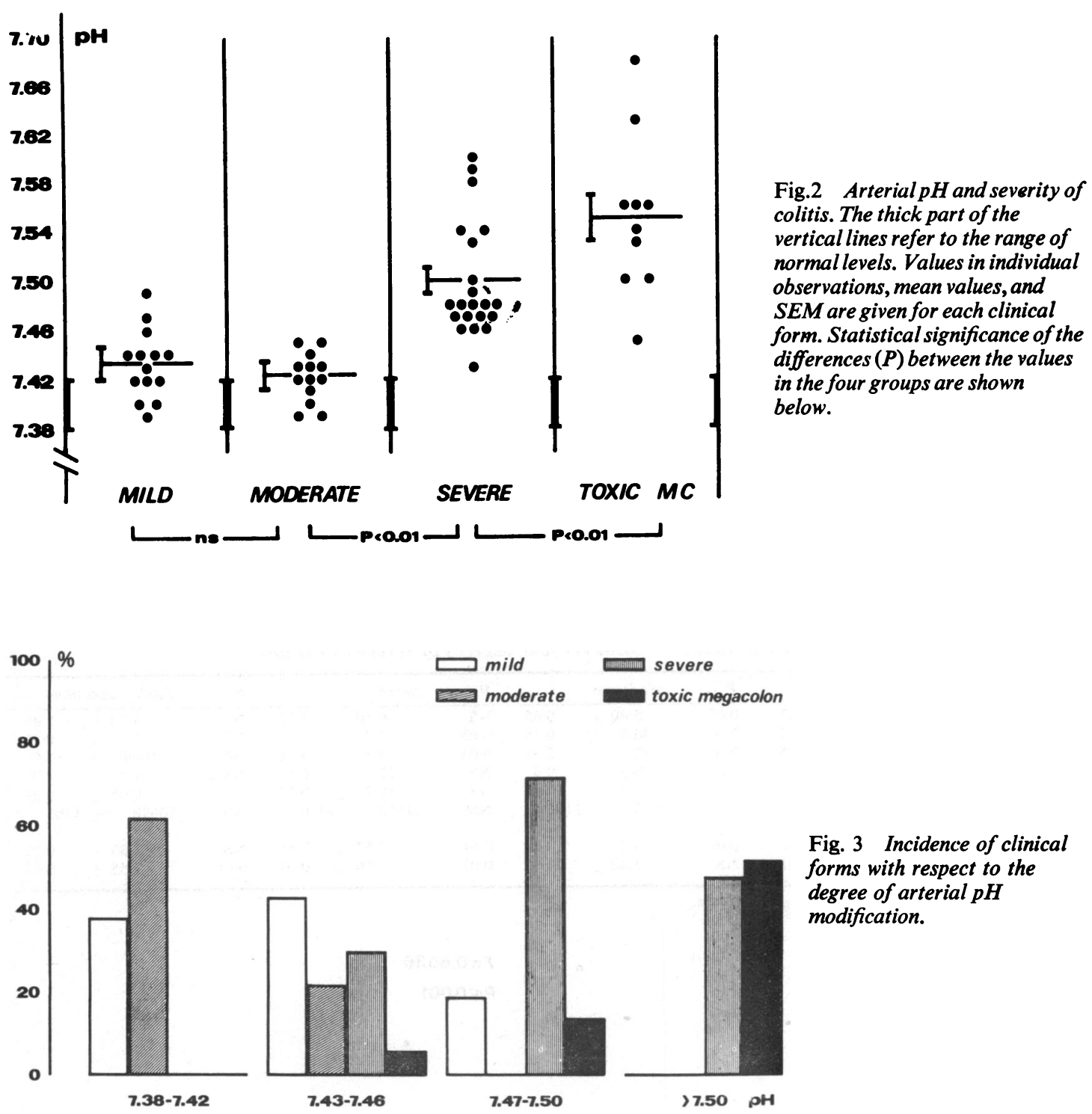

PH AND INTESTINAL GAS

A correlation was found between $\mathrm{pH}$ and gas in the small and large bowel $(r=0.5652)$ (Fig. 9). Table 3 shows the amount of intestinal gas in uncomplicated colitis and 'toxic megacolon'. Gas in the large bowel increased progressively as colitis became more severe; there was also a significant difference in the amount of small bowel gas between moderate and severe forms.

\section{Discussion}

It is widely accepted that the most common acid-base disturbance in patients with diarrhoea is metabolic acidosis and that diarrhoea rarely leads to a metabolic alkalosis (Editorial, 1966). A metabolic alkalosis typically occurs in congenital chloridiorrhoea (Evanson and Stanbury, 1965), but it has been observed also in a variety of diarrhoeal diseases 
— Moan ValuestSEM

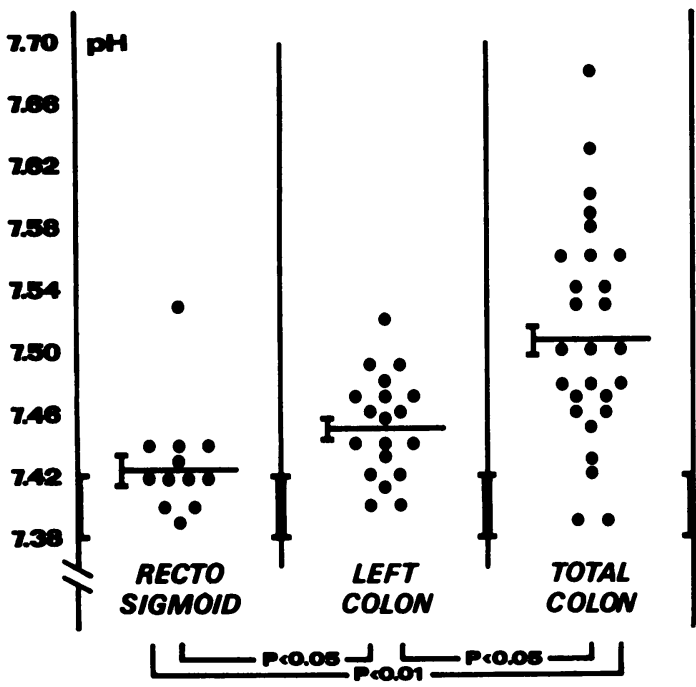

Fig. 4 Arterial pH and extent of colitis. Explanation as in Fig. 2.
(Caprilli and Vernia, 1975), including proctocolitis (Caprilli et al., 1974, 1975b). In proctocolitis metabolic alkalosis mainly results from intestinal loss of water, sodium, and chloride; a respiratory component, probably due to intracellular acidosis, may be present.

Data obtained in the present investigation confirm that changes in blood pH, expressed as metabolic or mixed alkalosis, is a characteristic feature of both severe and complicated colitis ('toxic megacolon'). Normal $\mathrm{pH}$ values were observed only in colitis of mild or moderate severity.

$\mathrm{pH}$ appeared to increase not only with the severity of the disease but also with the extent of the lesions. The increase in $\mathrm{pH}$ showed a close correlation with gaseous distension of the intestine, pulse rate, and plasma albumin and, to a lesser degree, with body temperature and ESR. No correlation was found between $\mathrm{pH}$ and frequency of bowel motions. In the 'toxic megacolon' patients of the present series, all of whom required surgery, the number of bowel motions varied from none to six.

Measurement of blood pH levels and plain $x$-ray films of the abdomen have been found to be the most reliable single methods for rapid detection of the

Table 2 Main clinical findings (mean values $\pm S E M$ ) in four degrees of severity of colitis

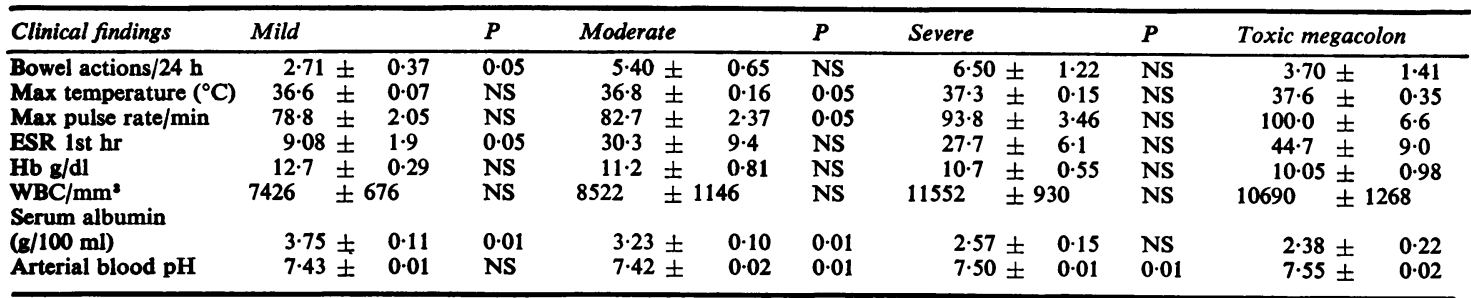

Statistical significance of the differences $(P)$ is given.

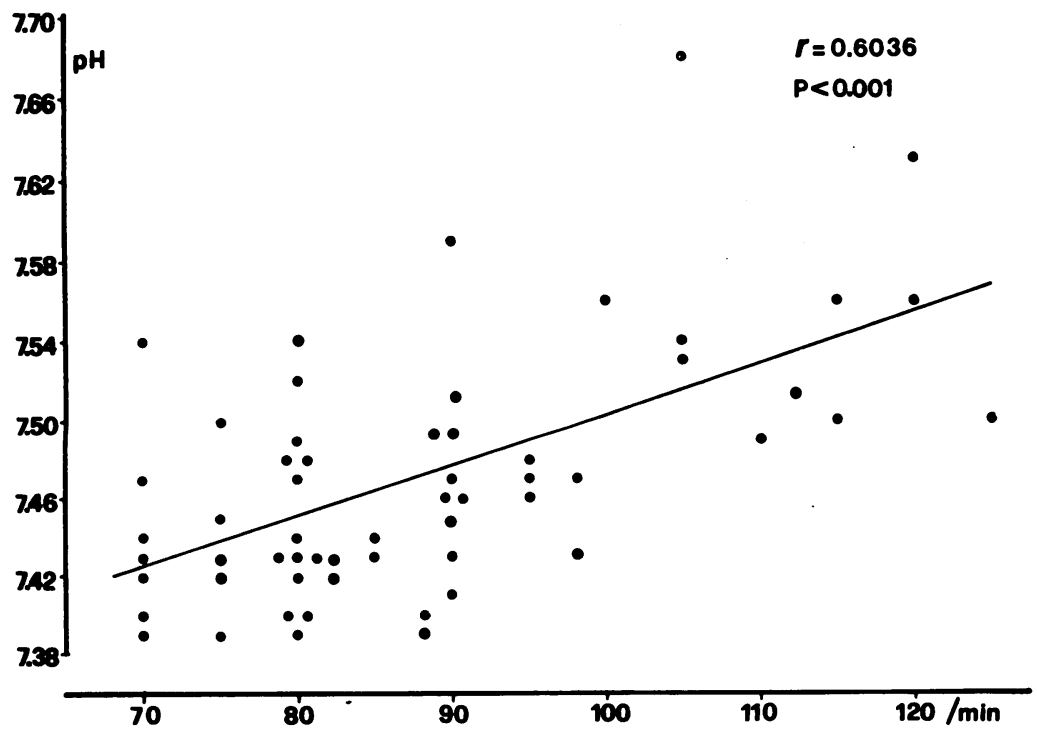

Fig. 5 Arterial $\mathrm{pH}-$ pulse rate correlation. 


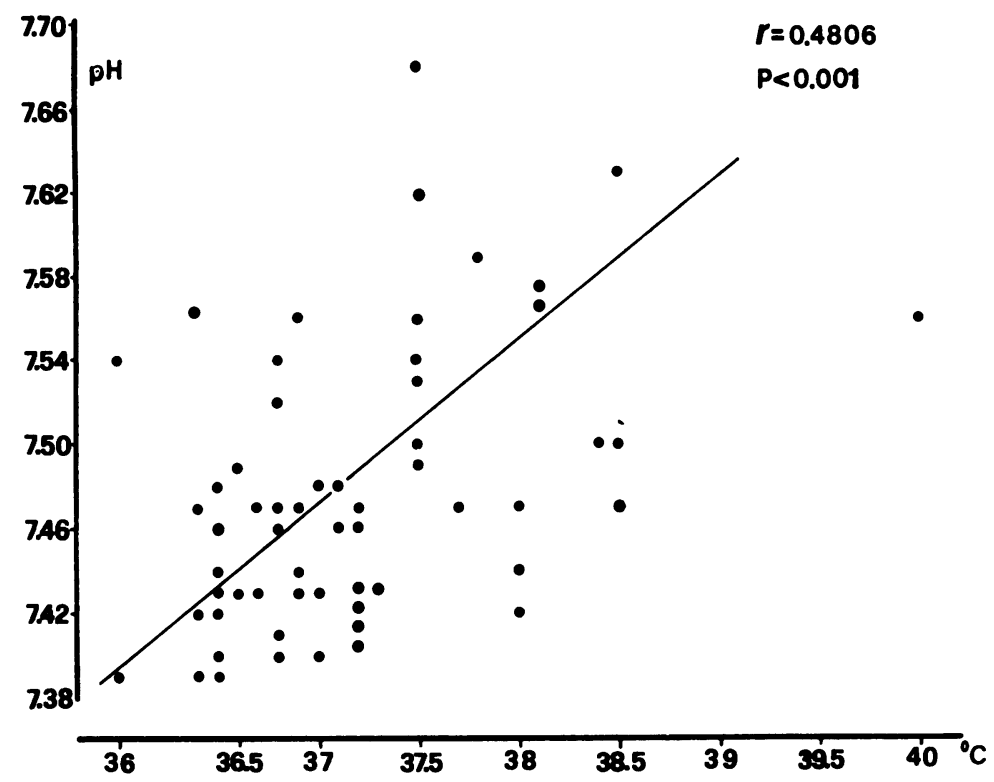

Fig. 6 Arterial $p H-b o d y$ temperature correlation.

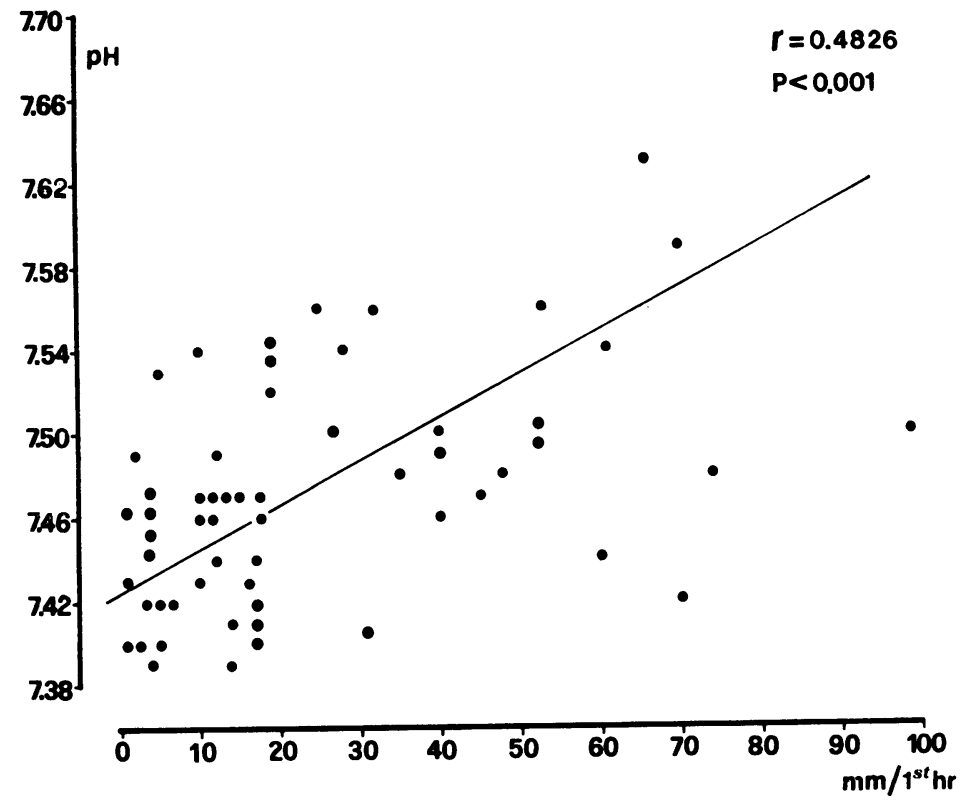

Fig. 7 Arterial $p H-E S R$ correlation.

early phases of intestinal dilatation, which may be associated with clinical signs that are only mild. A progressively increasing amount of intestinal gas, even though distension of the colon is less than $6 \mathrm{~cm}$ in diameter, and a blood $\mathrm{pH}$ above 7.50 should be regarded as 'alarm signs' that 'toxic dilatation' of the colon is impending. Further deterioration of this condition-'impending megacolon'-(Caprilli et al., 1975b; Torsoli, 1975) may be prevented by intensive medical care. 


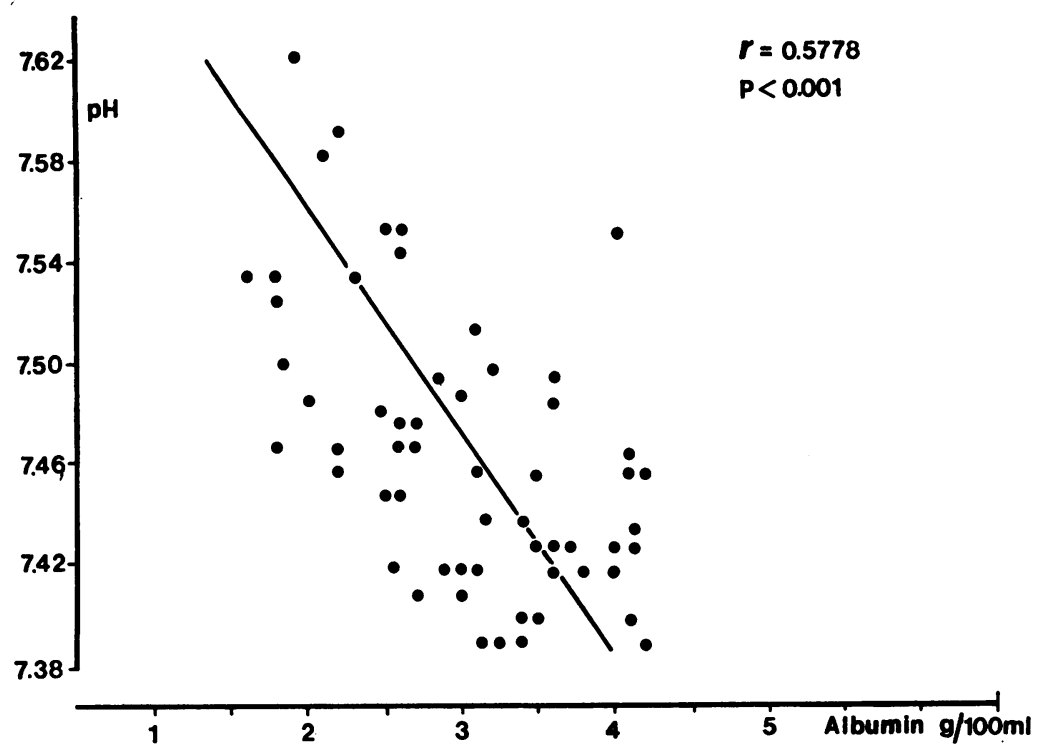

Fig. 8 Arterial $\mathrm{pH}$-plasma albumin correlation.

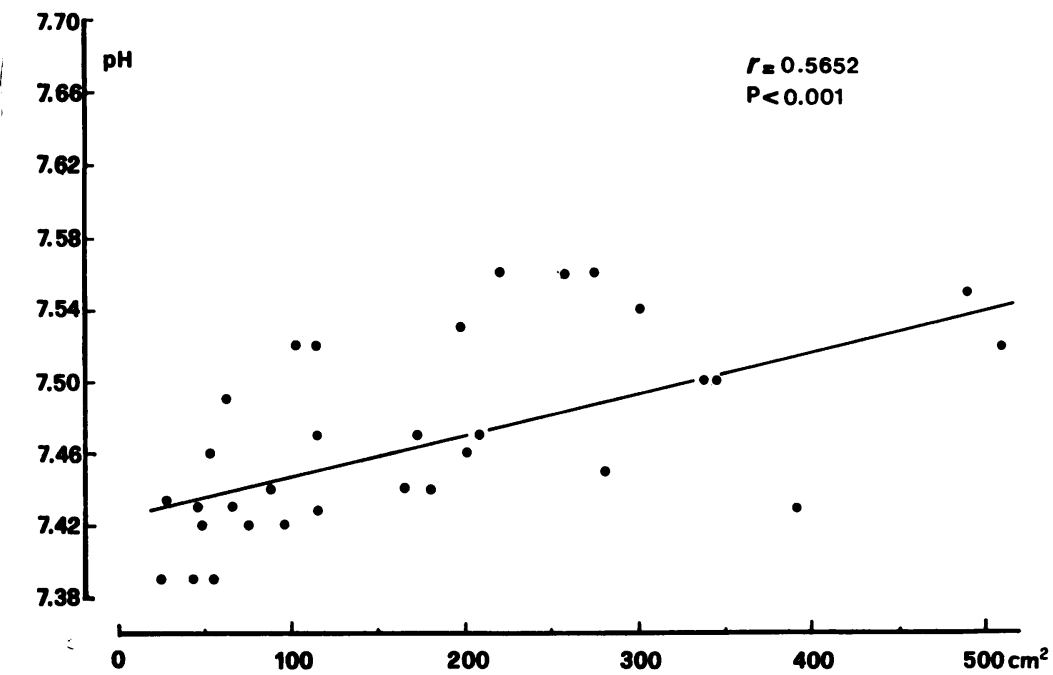

Fig. 9 Arterial pHintestinal gas correlation (32 cases).

Table 3 Intestinal gas, measured planimetrically $\left(\mathrm{cm}^{2}\right.$ mean values $\left.\pm S E M\right)$ in four degrees of severity of colitis

\begin{tabular}{|c|c|c|c|c|c|c|c|}
\hline Intestinal gas (cm²) & Mild & $\mathbf{P}$ & Moderate & $\mathbf{P}$ & Severe & $\mathbf{P}$ & Toxic megacolon \\
\hline $\begin{array}{l}\text { Small bowel } \\
\text { Colon } \\
\text { Total }\end{array}$ & $\begin{array}{l}25 \cdot 2 \pm 9 \cdot 05 \\
29 \cdot 2 \pm 3 \cdot 65 \\
54 \cdot 4 \pm 4 \cdot 81\end{array}$ & $\begin{array}{l}\text { NS } \\
0.05 \\
0.05\end{array}$ & $\begin{array}{l}30 \cdot 3 \pm 4 \cdot 21 \\
44 \cdot 8 \pm 4.47 \\
75 \cdot 1 \pm 6 \cdot 93\end{array}$ & $\begin{array}{l}0.05 \\
\text { NS } \\
\text { NS }\end{array}$ & $\begin{array}{r}74.0 \pm 11.8 \\
65.3 \pm 7.5 \\
139.3 \pm 18.5\end{array}$ & $\begin{array}{l}\text { NS } \\
0.01 \\
0.01\end{array}$ & $\begin{array}{r}76 \cdot 8 \pm \quad 8.0 \\
252.4 \pm 31 \cdot 8 \\
339.3 \pm 27.8\end{array}$ \\
\hline
\end{tabular}

Statistical significance of the differences $(P)$ is given. 
We are grateful to $\mathrm{Mr}$ G. Zapponi, Electronics Laboratories, Institute of Health, Rome, for his help in the statistical analysis of data.

\section{References}

Caprilli, R., Alessandrini, A., and Dotta, F. (1974). Metabolic alkalosis in 'toxic megacolon'. Rendiconti Gastroenterologia, 6, 23-28.

Caprilli, R., Carratu, R., and Babbini, M. (1975a). A doubleblind comparison of the effectiveness of azathioprine and sulphasalazine in idiopathic procotocolitis. American Journal of Digestive Diseases, 20, 115-120.

Caprilli, R., and Vernia, P. (1975). Acid-base disturbances in diarrhoea. Proceedings of the First International Symposium on G. I. Emergencies, Stockholm. Pergamon Press: Oxford. (In press).

Caprilli, R., Vernia, P., and Torsoli, A. (1975b). Fluid and acid-base imbalance in severe ulcerative colitis. In Proceed- ings of the First International Symposium on G. I. Emergencies Stockholm. Pergamon Press: Oxford. (In press).

Evanson, J. M., and Stanbury, S. W. (1965). Congenital chloridorrhoea or so-called congenital alkalosis with diarrhoea. Gut, 6, 29-38.

Lancet (1966). Diarrhoea and acid-base disturbances. (Editorial). Lancet, 1, 1305-1306.

Lennard-Jones, J. E., Ritchie, J. K., Hilder, W., and Spicer, C. C. (1975). Assessment of severity in colitis: a preliminary study. Gut, 16, 579-584.

Torsoli, A. (1975). Acute severe colitis: introduction. Proceedings of the First Internal Symposium on G. I. Emergencies. Stockhoim. Pergamon Press: Oxford. (In press).

Truelove, S. C., and Witts, L. J. (1955). Cortisone in ulcerative colitis: final report on a therapeutic trial. British Medical Journal, 2, 1041-1048.

Zer, M., Wolloch, Y., and Dintsman, M. (1972). Pitfalls in the surgical management of fulminating ulcerative colitis. Diseases of the Colon and Rectum, 15, 280-287. 